\title{
All the Memory in the World, All the Music in the World: Mediating Musical Patrimony in the Digital Age
}

\author{
ELODIE AMANDINE ROY, Newcastle University
}

\begin{abstract}
In this article, I will examine the internet through the lens of consumption and waste studies. The internet will be conceived of as the place where the cultural waste of music - in the form of marginal artefacts and obsolete media (such as vinyl records, tapes, and ephemera) - can effectively be excavated, recirculated and re-mediated by means of systematic digitisation and uploading. The redemptive role of popular and spontaneous digital archives (such as the video platform YouTube or dedicated audio blogs) will be critically examined.

Complementarily, I will underline the idea that the internet also encourages a paradoxical return of tangible artefacts, as the work of digital music collectors may prompt the actual reissue of previously lost music objects (a tendency that is exemplified in the UK by the work of British contemporary reissue record labels such as Trunk Records or Finders Keepers). The internet will be discussed as an ambiguous site of redemption, forming the basis for a nostalgic retro-consumption of music. As such, it will be conceived of as a site of memory and as a possible archive, though the ambiguity of such a term will be discussed. I will reflect upon the cultural meaning of digital archives that, as they are ceaselessly renewed, continue to erase themselves. Lastly, I will suggest that the forms of redemption that are enabled by the internet are strictly inseparable from the production of further layers of cultural waste. Departing from Straw's assertion that the internet 'has strengthened the cultural weight of the past, increasing its intelligibility and accessibility' $(2007,4)$, I will point out that the internet may accelerate the processes of cultural obsolescence and oblivion that it seeks to suspend.
\end{abstract}

\section{KEYWORDS}

New media, digitisation, music, archive, materiality, memory, cultural transmission.

\section{Introduction}

In the mid-1950s, the American-Italian architect Marino Auriti dreamed of building an 'Encyclopaedic Palace', in which the cultural knowledge and patrimony of the whole planet could be gathered and preserved, and subsequently be passed on to future generations. Auriti's Palace was mostly an imaginary archive, a project never to be completed, although a model of it was effectively built (see Gioni 2013). As Auriti was dreaming of his Encyclopaedic Palace, the French film director Alain Resnais paid homage to a 'palace' of another kind - the Bibliothèque Nationale in Paris - in the form of a film-essay called Toute 
la Mémoire du Monde (All the Memory in the World; 1956). His camera wandered patiently in the gigantic building of the Bibliothèque Nationale; carefully scripted descriptions, uttered by an absent narrator, accompanied the images. The Bibliothèque Nationale was referred to as a real and figurative 'fortress' from which no printed material may ever escape. At the time of filming, the library contained six million books and five million prints, with new material joining its collection on a daily basis. The library, for Resnais, was 'a model memory, stockpiling everything printed in France' (1956). The library is more precisely an archive, a physical and authoritative place of memory, and simultaneously a site of origin and power (Derrida 1996; Steedman 2001).

The will to shed cultural forms from the destructive work of time has long been expressed in macroscopic and monumental physical places (the palace, the archive, the library). At a smaller level, it may be argued that cultural artefacts themselves - such as, for instance, Resnais' film - function as miniature worlds in which human knowledge is discretely and partially stored. The dream of the total archive can evidently be linked back to the encyclopaedic spirit and fever of the Enlightenment, embodied in the figures of Diderot, Voltaire or Rousseau. Their Encyclopaedic project represented the first institutionalised attempt to capture and disseminate all the world's knowledge through the printed medium (an attempt largely made possible by the technological progress of the time). Whilst the dream of total knowledge of the world progressively crumbled under the ever-growing weight of knowledge (leading to the increasing fragmentation and ramification into specialised 'branches' and microcosms), the phantasm of a global, total and universally accessible archive lived on.

I will argue that the internet has renewed the dream of the universal archive and provided a place for the potential total archiving of the world's culture. As such, the internet might be considered as not simply a 'celestial jukebox' (Burkart and McCourt 2004) but also as the über-medium of archival memory, presenting itself as an apparently limitless place of storage as well as a means to retrieve past cultural objects and knowledge. The internet further functions not only as a tool for accessing and mediating past musical contents and memories, but perhaps also as a tool for organising the musical past. Straw argues that '[n]ew media $[\ldots]$ are perpetually producing the past in various forms of coherence' $(2007,14)$, thus suggesting that new interfaces and technologies enable us to revisit the cultural past and, most crucially, to delimit or legitimise it.

The main aim of this article is to provide an initial reflection upon the entwined notions of archiving and memory in the internet age. As such, the article aims to offer a few initial critical and theoretical considerations, rather than to deliver a strict 'snapshot' or exhaustive description of digital archives. My account is thereby of a necessarily limited nature. It will especially focus upon archives whose content is built by users, and which constitute one of the most notable challenges to traditional or institutional archives. The article relates back to music not to suggest that music is the only cultural form that was affected by digital archiving, but perhaps to think of user-generated digital music archives as exposing, in an idiosyncratic manner, the ambiguities and paradoxes of online cultural archives.

It must be noted that music has traditionally been an ambiguous and complex reality, at once immaterial (heard but not seen) and materialised (in the form of the sound-carrier), ephemeral 
(the performance) and recorded (the object). The idea of archiving or storing music is itself paradoxical. Unlike other traditional cultural objects (such as books and paintings or sculptures), music is not a 'real' object but is mediated by an object (the record). As such, the record is simultaneously a 'container' or, more especially, what Tim Dant calls an 'object that mediates' $(1999,154)$; in other words, it does not spontaneously or totally 'give' itself but it needs to be played to disclose its content. If the archive is understood as a site of mediation (where the past cultural memory is accessible for future retrieval), the music archive thereby mediates objects that mediate. The internet introduces a third degree in the mediation of music, for it further removes musical content (music objects are accessed online, through the medium of an interface, but not necessarily physically manipulated).

\section{The material patrimony of music}

When Thomas Edison invented the tinfoil cylinder phonograph in 1877, it became possible for the first time to inscribe sound on a carrier (original tinfoil cylinders were soon to be replaced with wax cylinders, and Emile Berliner's discs eventually replaced cylinders). Voices, which until then had been understood as signs of the essential fugitiveness of human life, could be 'redeemed' (Peters 2004, 177) or, in Edison's own term, immortalised. The phonograph was the first successful popular, mass-produced device that allowed for sound to be recorded and repeated at will. Music could suddenly - and magically - exist beyond the realm of the concert hall, outside the inexorably fleeting time of the performance. Divorced from 'real' time, the record would perform a mechanical memory of sound. It thus existed as a prosthetic medium that allowed for an artificial or synthesised memory to be transmitted over space and time. Phonography was part of a broader network of telecommunication and tele-presence technologies that emerged in the nineteenth century (telegraphy, telephony, but also photography which allowed for exact images to be displaced, and replicated, in time and space). These technologies were part, but also the means, of a still nascent yet irresistible process of capitalist industrialisation. Bernard Stiegler defines them as sites of 'industrialization of memory' $(2009,3)$. What he means is that memory, as it was synthesised by new technologies, became an essentially prosthetic form (detached from the individual's mind). It could therefore become a product or a commodity, and be disseminated via the structures of the capitalist industry (and its associated network of distribution). Although Stiegler does not use the word, he implicitly and consistently considers the industrialisation of memory to be a founding condition to mass culture, that is to say massively mediated culture.

In 1901, the first commercial recordings were pressed and distributed (Milner 2009, 37).Throughout the twentieth century, music has been commodified, and primarily been consumed as a specific object, ${ }^{1}$ endowed with its own material properties and associated playback devices. In this sense, music became a thing (Corbett 1994; Eisenberg 2005), with the media format seen as the main manifestation or 'reality' of music. The advent of recording led audiences to establish a new relationship to music and its 'objects', leading in some cases to a fetishism of the tangible music object. The introduction of phonographs and records - literal embodiments of the idea of music - thereby had a crucial influence on the socio-cultural understanding, consumption and production of music. It led, in a somewhat chaotic relationship, to the progressive establishment of a recorded musical culture, that is to say an object-based (as opposed to performance-based) culture. As noted by Greg Milner, 
recordings came to 'define the sound of [the] musical world' $(2009,12)$. An originally volatile sound, now strictly bound and contained, could become part of a material chain, gathering around itself new types of practices. One of these new practices was that of recordcollecting. Recorded music could be amassed in institutional or private sound archives for entertainment or research purposes.

Materiality allowed for the trade, commodification and general proliferation of music, as it allowed for its archiving and passing on; for its memory to survive (in a better, safer way than a written transcription would) (see Sterne 2003, 288). The first sound archive - The Phonogrammarchiv - was founded in Vienna in 1899. Personal collections denote, on a more discrete scale, the will to amass and collect the musical past. In 1947, a book titled How To Build A Record Library: A Guide To Planned Collecting of Recorded Music was published in the United Kingdom, meeting with resounding success in the world of collectors and future collectors of 78rpm shellac records (Elborough 2008, 44).

As noted by Jamie Sexton, "since the advent of recording technology, the "archive" of music recordings has continued to grow' (Sexton 2009, 99). The uninterrupted production of a material culture of music from 1901 until now can be seen as the base for the gigantic global archive, into which everything that was ever recorded and released implicitly participates. In his documentary, Resnais insisted upon the role of the Bibliothèque Nationale to catalogue every printed artefact ever published in France. However, there is no strictly equivalent institution for sound recordings: these constitute a phantomatic and scattered musical patrimony, to be found in personal music collections, institutional collections and secondhand markets (see Straw 2000). Obsolete or semi-obsolete cultural artefacts now inescapably saturate the visible and invisible spaces of the everyday, accumulating and recirculating in offline and online markets. The materiality of music, as it allows for the music object to age, also prevents it from utter and immediate disappearance. Because music was never entirely materialised but rather 'forced' into material formats, recorded sound is perhaps the easiest cultural object to dematerialise and thereby digitally archive and disseminate. In the early 1990s, the compact-disc provided the first instance of a digitally-synthesised sound signal. The digitisation anticipated the migration of recorded sound from its carrier, and ironically allowed for the digital music boom.

\section{Looking at user-generated archives}

\section{Users as historians?}

As a first remark, it may be argued that the notion of a digital archive is irremediably linked to (a) pre-existing ideas of what an archive is and/or should be (based on the early model of the physical archive); and (b) the pre-existence of a physical (and rather informal) musical patrimony. It follows that on a basic level, the digital archive may be seen as a transposition of the physical archive, where processes of music digitisation replicate the physical existence of music 'in the world'. The digital archive allows for a multitude of space-consuming objects to be miniaturised, easily transported, disseminated and exchanged. For instance, music and sound collections such as the ones held at the British Library have begun, through digitisation, to emancipate themselves from the physical limits of the library; they can now 
exist in the more immaterial realm of the internet and are theoretically accessible from any place in the world (provided it is connected to the internet). As such, although the digital archive can fulfil the functions of the traditional archive (storing musical contents for further reference and access), it is also identified by a specific mode and manner of access. This mode and manner of access - which can be described as 'dynamic' - has an impact upon the actual contents of the archive.

Digital and user-generated music archives may represent a spontaneous attempt to assess and gather disparate collections of recorded sound by networking them more explicitly. I will argue that digital interfaces such as YouTube (launched in 2005), Dailymotion (2005), and streaming websites/tools such as Last.fm (2002), Spotify (2006), Grooveshark (2007) and SoundCloud (2007) - as well as more discrete specialised audio-blogs and websites increasingly help concentrate the musical patrimony. The audioblog is a form of display of one's collection of unusual recordings or 'incredibly strange music', to borrow Andrea Juno and Vivian Vale's expression describing collectors of neglected and obscure music objects (1995 and 1993). Though there are important disparities between and within the interfaces mentioned above (some are legal interfaces, others not), all of them offer possibilities to upload musical content. Users, acting as popular archivists and (sometimes) archivists of the popular, carry out an intense work of curation and remediation. By digitising and uploading selected past recordings they contribute to the migration of disparate tangible music objects into the digital realm. For instance, in most audio blogs what is excavated and rescued by the 'vinyl archaeologist' (or phono-archaeologist, to use a less restrictive term) is not only an old or rare recording, but also the contexts that underpinned its creation and circulation.

Contemporary phono-archaeologists can be loosely associated with a figure developed in the writings of Walter Benjamin (1973), that of the indefatigable collector, more precisely that of the collector who is simultaneously a historical materialist. To be a historical materialist is to recognise, in the debris of cultural production from the past, underdeveloped potentialities. Such underdeveloped potentialities may include marginal moments and movements, seeds of the future in the past now crushed by the weight of traditional history. The collector, says Benjamin, is able to decipher in the objects which s/he collects signs that undermine conventional visions of the past. S/he considers history as that which is not linear and terminated, but a construction always already in the making, forever unmade and recombined. In other words, history is a growing reality, one that cannot be ignored and that ultimately belongs with the living.

Whilst Benjamin's collector was an identifiable member of the community, spontaneous digital archives 'belong' to the pro-active, yet curiously hidden, community of 'users'. YouTube is an example of a collaborative, accumulative and ownerless archive. It may be likened to a series of audio-visual samples or fragments, cyclically recomposed. In most cases, users do not legally own the rights for these samples. In an essay originally written in 1994, Chris Cutler examined the ways in which the recorded past is sampled, reused and rearranged by music practitioners. He exposed the basis for what he calls a plunderphonic form of art, and defined plunderphonics as 'a practice [that] radically undermines three of the central pillars of the art music paradigm: originality - it deals only with copies; individuality - it speaks only with the voice of others; and copyright - the breaching of which is a condition of its very existence' (Cutler 2004, 143). 
As such, plunderphonics is bound with the Western context of production, circulation and reception of music. It is dependent upon a pre-existing music industry. The concept of plunderphonia may be extended to include user-curated archives, where audio-visual contents are uploaded and rearranged. On another level, it may be said that even the interface results from a form of plundering. Streaming websites frequently imitate former contexts of playback: the tracks are organised in 'albums', 'collections' and 'playlists' (Bolter and Grusin 2000, 45). The image of the past is revived. Most streaming websites offer options to the user for collecting his/her favourite files. On Grooveshark one can add to one's 'collection' by clicking on the file, whilst YouTube allows its users to add videos to their own channels. Yet, despite the possibility to personalise one's online collection, an important feature of the collector also disappears: his/her sense of ownership. Benjamin, in his 1931 essay on book collecting, describes ownership as 'the most intimate relationship that one can have to objects. Not that they come alive in him; it is he who lives in them' $(1973,67)$. Yet streaming and owning are two different things. It can be argued that the possibility of hearing music replaces the ownership of the musical object or even the commodity. In other words, as argued by Tom Court (2005), the digital collector collects an immaterial flux or stream, virtually or symbolically possessing what is, indeed, caught in the constant process of passing.

For Benjamin (1973), the material properties of the object were crucial in its role as cultural and historical artefact. Yet digitisation removes the object from the flow of time as it were, by providing 'perfect copies forever'. Or, if the copies are not perfect, their development is arrested in time. From the moment an object has been digitised, it will not age any more; it exists in different conditions. Where the Benjaminian collector owned an original, or at least a physical copy of something that had been made at a specific moment in the past, what now survives is a digital copy of the object. This is notably because of the apparently ahistorical nature of digital objects that, though they do have a 'birthdate' (that is to say they were created at a given moment), fail to 'age' according to the laws of the physical word. As such, although an MP3 file can be damaged and decays in a particular way, it is more likely to be erased in one click. Tom McCourt, in his analyses of the digital music collector, has argued that because of its lack of degradation, the digital music file could not record history (whilst the passing of time may be inscribed upon the surface of a physical music object). He writes that, 'through their immateriality, digital files cannot contain their own history. Unless they are burned onto a $C D$, they have no physical manifestation. No history is encoded on their

surfaces, since they have no surfaces' $(2005,250)$. Furthermore, a digital file is never actually the same; it constantly recomposes and certainly cannot be considered to be unique (unless, of course, it was never duplicated and disseminated). As such, an online music archive preserves images or illusions of music objects, sheltered from the actual process of aging.

\section{Instant archive and archives of instants}

YouTube functions as an instant archive, and perhaps also as an archive of instants, brief fragments of conversations, audio-visual monads or clips. It is common that recordings, which had originally been gathered in albums, are fragmented again. Here only one or two songs are salvaged and uploaded, depending on the personal tastes of the user. The album ceases to make sense as a totality and it may be argued that it is notably the distinct media format imposed by the music industry (one LP record, one compact-disc) that brought it together as a homogeneous object in the first place. YouTube may be seen as a means of encouraging a practice of 'zapping', where one video leads to another, often through 
accidental or hazardous pathways. In other words, what is accessed in the archive is not necessarily that for which the user was originally looking, but an approximation of the object he/she was trying to locate. This is further supplemented by the fact that there is not as yet any strict 'catalogue' of the internet, but rather search engines and keywords. In his documentary, Resnais insists that 'without a catalogue, this fortress [the Bibliothèque Nationale] would be a pathless land' (1956).

The instant archive is conversely an archive in the making, the paths of which are constructed with every new internet search, only to be effaced again. It may be said that no two routes are the same but that every quest for information may slightly differ from another. The paths used to reach the information are created at the moment when the user proceeds to the online search. Such paths conversely disappear once the search has been completed, for the internet is a dynamic structure, one that cannot be frozen or stabilised. In a paper exploring the role of ICT (and notably websites and weblogs) in the preserving and playing back of marginal memories, Tamar Ashuti proposes that

unlike the mainstream media, typified by the linear representation of symbolic content, the Internet allows for interactive consumption of its contents. This unique feature contributes to the creation of a more active experience of consumption, in which the consumer of joint memory functions also as its editor, and, as such, its producer. $(2011,112)$

It can be suggested that users relate to archived content in a creative way. Examples of this include the creation of homemade footage to illustrate musical contents, mash-ups, creation of playlists, covers and comments.

\section{Open-ended and mono-mediated archives}

The internet is an open-ended archive. As such, it cannot be compared to the traditionally closed building of the archive, bound in space as well as time. The most salient feature of dynamic digital archives, especially user-generated ones, is that, instead of locking memories in a specific space, they deform and displace them, reforming them forevermore. This is notably because the content of the archive can be endlessly reshaped, copied and disseminated. For instance, a YouTube video might migrate to other interfaces and be embedded in webpages. At this point, YouTube can be envisioned as a paradoxical 'archive', whose contents are not stable but constantly disseminated. Some of them exist in numerous forms and copies (the same material may have elicited various answers from the users). The archive shelters no original (unique and irreproducible) object; rather, it presents the reproduced echoes or auras of the missing original object. The suggestion of a 'creative' work of memory is all the more valid when one considers that virtually any new content may be added at any point to the archive, as if to suggest that the object of memory remains out of reach.

The constant increase of digital contents and their indiscriminate circulation may allow us to speak of an 'information explosion' (Castells 2001) or a 'memory boom' (Huyssen 2003), where information and memory collide, circulating through the same digital networks. All internet content is 'translated into separate bytes consisting of strings of ones and zeros' that can be stored and accessed 'in virtually unlimited amounts and at virtually unlimited speed' (van Dijk 2006, 191). The different types of memory formats (film, sound recordings, text) 
merge into what Zielinski calls a 'monomedium' $(2006,31)$. The specificity of these media, and the particular ways in which they age, are thereby no longer prime components in the transmission of content. This is partly because (as we have seen) these contents are not strictly different and each presents itself in a similarly atemporal manner on the screen.

In this section, user-generated music archives have been described as places where the musical past is articulated in a non-linear fashion and by a large community of users whose aims do not coincide. What is offered is not one vision of the past, but a creative and ludic kaleidoscopic vista, betraying a heterogeneous and unstable reality. I would argue that the historicity of the musical material (as it was previously encountered and embedded in a specific material form) is partially liquidated: the musical past, mediated by a new interface, may appear as a novelty itself. The monomedium is at the same time a flattening of media differences. Yet there are specific ways in which the old medium is still visible beneath the new medium. A common way for music collectors to present their collection online is to film it, or to film a record spinning on a turntable for example, in order to capture again the particular grain and noise of the recording. The image of the original medium, in some ways, re-historicizes the recording. The digitisation of the old medium itself allows for the music as well as the 'surface noise' of history to be preserved. Other ways of nuancing or fragmenting the monomedium of the internet can be found in the physical recirculation of digital contents, or in the revival of pre-digital cultural forms (such as, for instance, the resurgence of vinyl LPs or cassette tapes). In the second part of the article, I will focus on the recirculation of physical music objects beyond the digital realm in order to provide a corrective to the view of the internet as that which absorbs the totality of the material culture of music.

\section{The second life of musical fossils: nostalgia and circuits of retro-consumption}

\section{Retro-media, retro-mania}

It would be incorrect to assume that the omnipresence and apparent pervasiveness of digital technologies in Western everyday life corresponds to the systematic effacement of tangible objects. If the internet has often been held responsible for the reshaping, if not the demise, of the music industry (see Rogers 2013), and led record companies to adapt to digital markets, it has also paradoxically encouraged the recirculation and consumption of tangible cultural artefacts from the past. John D. Davis (2007) has described the contemporary intensification of the practice of record-collecting and discussed the emergence of the contemporary 'vinylphile', whilst the British music magazine The Wire recently dedicated a column to the 'vinyl bubble' (Sevier and Shipley 2013). ${ }^{2}$ In October 2007, an essay published in Wired magazine similarly engaged with the LP format and reflected upon the curious prevalence of vinyl records over digital formats (van Buskirk 2007). These are but a few contributions to the 'vinyl debate'. What can be noted is that in most cases the vinyl record - an iconic cultural medium of the past - is (sometimes romantically) seen as a means of direct access into the past and, more specifically, a past that is qualitatively better than the present (a core axiom of nostalgia). As such, purchasing and playing vinyl records distinctively historicises the listening experience by means of a fetishised medium. It removes the experience from the current technological sphere (framed by digital media) or, perhaps, merges technological times together: a recently recorded track can be embedded within an old format. The present is released or broadcast through the past - the electronic subgenre of hauntology is an 
especially striking example of this.

Specific reissue record labels (these include Finders Keepers and Trunk Records in the UK) set out to rerelease material on vinyl records (its original format), as if to indicate that the form almost matters more than the content (or, at any rate, is a part of that content). This practice can be read in contrast with earlier reissue record labels, such as the American labels Folkways (founded in 1948) or Yazoo (1967). Both Folkways and Yazoo reissued material originally released on 78rpm shellac records, in the formats that corresponded (at the time of reissuing) to the latest and most commonly used technological formats. The marketing of archival content in its original format is a new phenomenon, one that often indicates an indefatigable nostalgia. The practice of releasing vinyl records is also frequently supported by the claims that former sound-reproduction technologies prove more satisfying to the true 'audiophile' than current ones - an aspect that remains open to discussion as new vinyl records, often pressed from digitally recorded and mastered files, can only superficially imitate their predecessors. The vinyl revival can be situated within a larger cultural thirst for 'retro' artefacts and effects - examples of which can be found in areas as diverse as fashion, film, photography or cooking. The appeal of 'retro' products and heritage sites has been evidenced in the UK since the 1980s (Wright 1985; Samuel 1994), although it can be argued that the idealisation of the past is not a strict characteristic of contemporary times (Thompson 1979; Guffey 2006).

The success of an auction website such as eBay seems to indicate that increased digitisation of the cultural world is an incentive for the recirculation of 'real' cultural and technological artefacts (Hillis, Petit and Epley 2006). This recirculation is one of the central themes of Simon Reynold's Retromania: Pop Culture's Addiction to its Own Past (2011), a book in which the author points out that much of today's cultural consumption takes the form of a retro-consumption. Reynolds examines the role of digital collectors in the revival of past musical trends, arguing that nostalgia for past cultural forms is a direct correlative of their availability. In other words, it may be that the general and literal visibility of past recordings in a digital form kindles nostalgic desires for their three-dimensional incarnations (as digitisation only gives the image of a record, implicitly indicating the absence or loss of the physical object). Nostalgia, here, does not denote a will for history, but rather blurs it. Where Benjamin's historical materialist seeks to rescue and release the effective potentialities caught in the cultural object, nostalgia is a 'consumer-algia' - a longing for a bygone mode of consumption. Finders Keepers (founded in 2005) or Trunk Records (1996) indiscriminately release material from the past, following no specific agenda or organisation. Finders Keepers' catalogue is a Wunderkammer, gathering film soundtracks from the Czechoslovakian New Wave era, musique concrète, and Welsh music, as well as Pakistani pop hits from the 1970s. Underpinning contemporary reissue record labels are the aesthetics of the found object: the collections they release are truly heterogeneous, offering no or little organising of the musical past. The new 'archives' thus constituted are possibly debatable; for them to be viable, the label founders need to constantly rescue and market 'marvels' from the (apparently inexhaustible) recorded past, trawling both the physical and digital world in order to do so. ${ }^{3}$ They do not offer any deep historical accuracy, as they often contextualise their findings in a mythical or idealised past. But perhaps it is because they determinedly align themselves with the more ludic or childish side of collecting, where history vanishes in the face of a heteroclite collection of curiosities. 


\section{The life-cycle of rubbish}

If, as proposed above, digitisation accelerates redemption then it might be argued that it also flattens the perception of history; indeed, every music object may be available and rediscovered at all times. In such a case, quantity seems to absorb qualitative differences between objects, whose existence appears as indiscriminate and 'en masse'. In the two volumes of Incredibly Strange Music - respectively published in 1993 and 1995 - Juno and Vale have retraced the steps of pre-digital music collectors, rummaging through NorthAmerican junk stores and second-hand record shops in the hope of redeeming (through the act of purchasing) forgotten gems, or other's people rubbish. Rubbish - exposed in the form of masses of unwanted wares - is a 'by-product' of production (Thompson 1979, 114). It might also become the most visible aspect of production on the internet, where the production of more than one century of recorded music is represented. On the one hand, increasing processes of digitisation, supported by various governmental institutions (such as the UK's British Library Sound Archive), academic or semi-academic projects (e.g. King's College Sound Archive, The Women's Liberation Music Archive), and non-governmental, spontaneous undertakings may help salvage neglected and underappreciated music objects. On the other hand, the internet may favour indiscriminate processes of archiving, leading to the systematic archiving of ephemeral objects. For it is a given that a digital file can never completely disappear; it lingers on.

The internet has an interesting relationship to transience in that it does not allow for the total erasing of traces: information remains, even though it is not necessarily accessed. In the earliest pages of Rubbish Theory, Michael Thompson describes objects as belonging either to the transient or durable category, where '[o]bjects in the transient category decrease in value over time and have finite life-spans' whilst '[o]bjects in the durable category increase in value over time and have (ideally) infinite life-spans' (1979, 7). Thompson introduces the category of rubbish as the link between the transient and the durable, to explain how a transient object may be preserved and enter the category of the durable. The category of rubbish is an in-between category where the object is neither alive nor dead, but caught between forgetting and redemption. As such, rubbish should not be heard in the mundane sense of 'garbage' but rather as an intermediary stage of the life-cycle of objects. I would like to argue that the internet makes this intermediary stage more durable by making perennial a phase that was not initially supposed to last.

\section{Conclusion}

Digitisation is routinely seen as a way of prolonging the life of tangible music objects. It allows for vast quantities of sound to be stored and distributed on a worldwide scale. It also indicates new ways of storing and transmitting culture, but also of conceptualising it, so much so that the internet can appear to be a total or continuous archive. And yet, if and when everything can potentially be saved, it may also be that nothing is quite remembered. Pierre Nora famously reflected upon the shape of memory in the twentieth century, and described a prosthetic memory that developed in tandem with photography, phonography, film and computers. He affirmed that ' $[\mathrm{m}]$ odern memory is, above all, archival. It relies entirely on the materiality of the trace, the immediacy of the recording, the visibility of the image' (Nora $1989,13)$. Perhaps the internet, an archival space par excellence, is simultaneously a place 
where archiving - in its first meaning - is impossible. A user-generated archive such as YouTube seems to accelerate the formation and fossilisation of cultural waste, notably because of the quickness with which contents are archived and the ever-increasing quantity of online contents. The dynamism of the archive may, in this case, be paired with a certain degree of inertia. The sociality and interactivity of online archives are indisputable, yet their role in the longer temporal continuum (and their role as a shaping historical force) is yet to be determined. The very principle that animates the user-generated digital archive (its dynamism) prevents it from constituting a legible site of transmission (a bridge between present and future generations). It might be that the experience of digital encyclopaedic palaces is, simultaneously, an experience of encyclopaedic ruins.

\footnotetext{
${ }^{1}$ Amidst these objects the most popular have been $78 \mathrm{rpm}$ shellac phonograph records, 33rpm vinyl records (introduced in 1948), 45rpm records, cassette tapes, and compact discs.

${ }^{2}$ It is worth noting that The Wire magazine promotes genres of music which are mainly, if not exclusively, released on vinyl records or cassette tapes.

${ }^{3}$ Between 2005 and 2013, Finders Keepers have released almost eighty artefacts. It might not be coincidental that the emergence of Finders Keepers parallels the rise of YouTube (both began to be active in 2005).
}

\section{References}

Ashuti, T. (2011) 'Joint Memory: ICT and the Rise of Moral Mnemonic Agents', in M. Neiger, O. Meyers and E. Zanberg (eds), On Media Memory: Collective Memory in a New Media Age, Basingstoke: Palgrave Macmillan, pp. 104-13

Benjamin, W. (1973) Illuminations. London: Fontana

Bolter, J. D. and Grusing, R. (2000) Remediation: Understanding New Media, Cambridge, Cambridge, MA and London: MIT Press

Burgess, J. and Green, J. (2009) YouTube: Online Video and Participatory Culture, Cambridge: Polity Press

Burkart, P. and McCourt, T. (2004) 'Infrastructure for the Celestial Jukebox', Popular Music, 23(3), 349-62

Castells, M. (2001) The Internet Galaxy: Reflections on the Internet, Business, and Society, Oxford: Oxford University Press

Corbett, J. (1994) Extended Play: Sounding Off from John Cage to Dr. Funkenstein, Durham and London: Duke University Press 
Cutler, C. (1994) 'Plunderphonia', in C. Cox and D. Warner (eds), Audio Culture: Readings in Modern Music, New York: Bloomsbury Academic, pp. 138-56

Dant, T. (1999) Material Culture in the Social World: Values, Activities, Lifestyles. Maidenhead: Oxford University Press

Davis, J. D. (2007) Going Analog: Vinylphiles and the Consumption of the Obsolete, in C. R. Acland (ed.) Residual Media, Minneapolis and London: University of Minnesota Press, pp. 222-36

Derrida, J. (1995) 'Archive Fever: A Freudian Impression', Diacritics, 25(2), 9-63

Eisenberg, E. (2005) The Recording Angel: Music, Records and Culture from Aristotle to Zappa, Yale: Yale University Press

Elborough, T. (2008) The Long-player Goodbye: How Vinyl Changed the World, London: Hodder \& Stoughton

Gioni, M. (2013) 'The Encyclopedic Palace', [online]. Accessible at http://www.labiennale.org/en/art/exhibition/gioni/. Accessed 6 November 2011

Guffey, E. E. (2006) Retro: The Culture of Revival, London: Reaktion Books

Hillis, K., Petit, M. and Scott-Epley, N. (eds) (2006) Everyday eBay: Culture, Collecting, and Desire, New York: Routledge

Huyssen, A. (2003) Present Pasts: Urban Palimpsests and the Politics of Memory, Stanford: Stanford University Press

Juno, A. and Vale, V. (eds) (1993) Re/Search \#14: Incredibly Strange Music, Volume I, San Francisco: Re/Search Publications

--- (eds) (1995) Re/Search \#14: Incredibly Strange Music, Volume II, San Francisco: $\mathrm{Re} / \mathrm{Search}$ Publications

McCourt, T. (2005) 'Collecting Music in the Digital Realm', Popular Music and Society, 28(2), 249-52

Milner, G. (2009) Perfecting Sound Forever: The Story of Recorded Music, London: Granta 
Neiger, M., Meyers, O. and Zanberg, E. (eds) (2011) On Media Memory: Collective Memory in a New Media Age, Basingstoke: Palgrave Macmillan

Nora, P. (1989) 'Between Memory and History: Les Lieux de Mémoire', Representations, 26, 7-24

Peters, J. D. (2004) 'Helmholtz, Edison, and Sound History', in L. Rabinovitz and A. Geil (eds), Memory Bytes: History, Technology, and Digital Culture, Durham and London: Duke University Press, 177-98

Resnais, A. (1956) Toute la Mémoire du Monde [film], France

Reynolds, S. (2011) Retromania: Pop Culture's Addiction to its own Past, London: Faber \& Faber

Rogers, J. (2013) The Death and Life of the Music Industry in the Digital Age, New York and London: Bloomsbury Academic

Samuel, R. (1994) Theatres of Memory - Volume 1: Past and Present in Contemporary Culture, London and New York: Verso

Sevier, R. and Shipley, K. (2013) 'Collateral Damage: Numero Group on the Vinyl Bubble', The Wire, 353, June. Accessible at http://thewire.co.uk/inwriting/essays/collateral-damage numero-group-on-the-vinyl-bubble. Accessed 25 June 2014.

Sexton, J. (2009) 'Digital Music: Production, Distribution and Consumption; Case Study: the i-Pod', in G. Creeber and R. Martin (eds), Digital Culture: Understanding New Media, Maidenhead: Open University Press, 92-106

Steedman, C. (2001) Dust: The Archive and Cultural History, Manchester: Manchester University Press

Sterne, J. (2003) The Audible Past - Cultural Origins of Sound Reproduction, Durham and London: Duke University Press

--- (2012) MP3: the Meaning of a Format, Durham and London: Duke University Press

Stiegler, B. (2009) [1996] Technics and Time, 2: Disorientation, Stanford: Stanford 
University Press

Straw, W. (2000) 'Exhausted Commodities: The Material Culture of Music', Canadian Journal of Communication, 25(1), [online]. Accessible at http://cjconline.ca/index.php/journal/article/view/1148/1067/. Accessed 8 Janurary 2014 --- (2007) 'Embedded Memories', in C. R. Acland (ed.), Residual Media, Minneapolis and London: University of Minnesota Press, 3-15

Thompson, M. (1979) Rubbish Theory: The Creation and Destruction of Value, Oxford: Oxford University Press

van Buskirk, E. (2007) 'Vinyl May Be Final Nail in CD's Coffin', Wired.com, 29 October. Accessible at http://archive.wired.com/entertainment/music/commentary/listeningpost/2007/10/liste ningpost_1029. Accessed 26 June 2014.

van Dijk, J. A. G. M. (2006) [1991] The Network Society: Social aspects of New Media, London: Sage

Wright, P. (1985) On Living in an Old Country: The National Past in Contemporary Britain, London: Verso

Zielinski, S. (2006) Deep Time of the Media: Towards an Archaeology of Hearing and Seeing by Technical Means, Cambridge, MA and London: MIT Press 